\title{
THE IMPORTANCE OF LINEAR LANDSCAPE ELEMENTS FOR BATS IN A FARMLAND AREA: THE INFLUENCE OF HEIGHT ON ACTIVITY
}

\author{
ROBERTO TOFFOLI \\ CHIROSPHERA Associazione per lo studio e la tutela dei chirotteri e l'ambiente, Via Tetti \\ Barbiere, 11 I 10026 Santena TO, Italy.e-mail rtoffoli@iol.it
}

Received: $16^{\text {th }}$ February 2016, Accepted: $6^{\text {th }}$ May 2016

\begin{abstract}
In the past 50 years, widespread removal of hedges and hedgerows in many European regions, with a consequent reduction in biodiversity, has occurred as a result of farming intensification. Acknowledging the ecological importance of linear farmland landscape elements, many agro-environmental schemes provide financial support for the management, conservation and reconstruction of hedges and hedgerows. The efficacy of such initiatives, also aimed at bat conservation, could be enhanced by including the role of hedges and hedgerows correlated to the variability of their physical structure and to the surrounding landscape context. Linear landscape elements are in fact of great importance to bats, whose flight activity tends to increase in proximity to hedges and hedgerows, used both during foraging and as commuting routes. Nevertheless, information concerning the correlation between various physical structures of hedges and flight and foraging techniques in bats is still lacking. The present study analyses the activity of bats along two different hedge types, with and without trees, and in open spaces, in an area of the Padana plane (North-western Italy) as a function of different flight behaviours.

Activity in bats appears higher along hedges than in open spaces but no significant differences are noted between the various hedge types under investigation. Foraging behaviour is primarily detected along hedges with trees but is lower along hedges without trees and in open spaces. This is particularly evident in bat species that have adapted to foraging in closed spaces surrounded by foliage (Myotis and Plecotus genera) or at the periphery of these environments (Pipistrellus genus), whereas it not seen species that forage in open spaces (Nyctalus genus). Hedge reconstruction aimed at bat conservation ought to, therefore, favour tall hedges with trees as opposed to low hedges without trees.
\end{abstract}

Key words: Bats, linear landscape elements, hedgerows, acoustic monitoring, bats conservation

\section{INTRODUCTION}

Farmland landscapes are traditionally pieced together as mosaics of cropland and various semi-natural environments. These landscapes have preserved a relatively high level of biodiversity despite the man-induced changes they have had to withstand (Antrop, 2005; Jonsen \& Fahrig, 1997; Robinson et al., 2001; Weibull et al., 2000). Hedges and hedgerows are characteristic elements of these landscapes and play a key role in supporting farmland 
Toffoli R.: The importance of linear landscape elements for bats in a Farmland area: the influence of height on activity

biodiversity. Hedges and hedgerows contribute to structural heterogeneity of the landscape, ensure connectivity between habitats and floristic diversity, are suitable environments for reproduction and offer shelter and food resources for many wildlife species (Burel, 1996; Dover \& Sparks, 2000; Hannon, 2009; Hinsley \& Bellamy, 2000; Tattersall et al., 2002; Whittingham et al., 2009), including a number of declining species in Europe (Robinson \& Sutherland, 2002). In the past 50 years, increased farming has led to widespread removal of hedges and hedgerows in many European and extra-European countries (Baltensperger, 1987; Sklenička et al., 2009), leading to a reduction in biodiversity as a consequence of landscape homogenisation (Benton et al., 2003; Bianchi et al., 2006). Recognising the importance of linear landscape elements for ecology, many agro-environmental schemes envisage financial support for the management, conservation and reconstruction of hedges and hedgerows (Regione Piemonte, 2015). The efficacy of these initiatives, in terms of costs and benefits for the protection of biodiversity, can be improved by incorporating the role of hedges and hedgerows correlated to the variability of their physical structure and to the context of the surrounding landscape.

Linear landscape elements are of a great importance to bats, whose activity tends to increase in proximity of hedges, hedgerows or forest margins, and are used both in foraging activities and as commuting routes (Krull et al., 1991; Entwistle et al., 1996; Walsh \& Harris, 1996; Verboom \& Huitema, 1997; Downs \& Racey, 2006; Boughey et al., 2011; Kelm et al., 2014). This may partly be due to the need of orientation landmarks for echolocation in bats, as linear landscape elements are used as reference points and guidelines during flight (Schnitzler et al., 2003; Schaub \& Schnitzler, 2007). The importance of hedges and hedgerows in habitats visited by bats is, therefore, linked to the increase in connectivity, especially in a fragmented landscape such as farmland.

In addition, hedges make up important foraging sites due to the abundant and diversified presence of prey (Maudsley, 2000; Pollard \& Holland, 2006), and function as wind shields, reducing energy consumption during flight and improving efficacy during foraging (Verboom \& Spoelstra, 1999).

Despite the importance of linear landscape elements, little is known about the correlation between their physical structure and the activity of various bat species as a function of the different flight and hunting techniques they adopt.

This work analysed bat activity as a function of different hedge types, in proximity or away from them, reconstructed with agro-environmental funds in an organic farming company. The aim was to improve the efficacy of bat conservation in financial support initiatives of management and reconstruction of linear landscape elements in the context of rural development programs.

\section{MATERIALS AND METHODS}

\section{Study area}

The study was carried out in a 40 hectare farm in the county of Valenza (Piedmont, North-western Italy, (Fig.1), characterized by organic cereal and horticulture crops. In 2005, $3062 \mathrm{~m}$ of hedge were reconstructed with the financial support of agro-environmental EU funds for rural development (2000-2006). Hedges consisted of the following tree and shrub species: Sambucus nigra, Prunus spinosa, Crataegus monogyna, Rosa arvensis, Cornus sanguinea with the addition of individual specimens of Populus nigra, Prunus avium, Acer campestre, Quercus robur and Carpinus betulus. Trees and shrubs were subdivided into: 1) hedges uniquely consisting of shrub species, lacking trees and with a maximal height of $2 \mathrm{~m}$ 
(735 m long, 24\% of the entire length) and 2) hedges including trees, with a total height of more than $2 \mathrm{~m}$ ( $2327 \mathrm{~m}$ long, $76 \%$ of the total length).

\section{Fig. 1: Study area and location of the surveyed hedges}
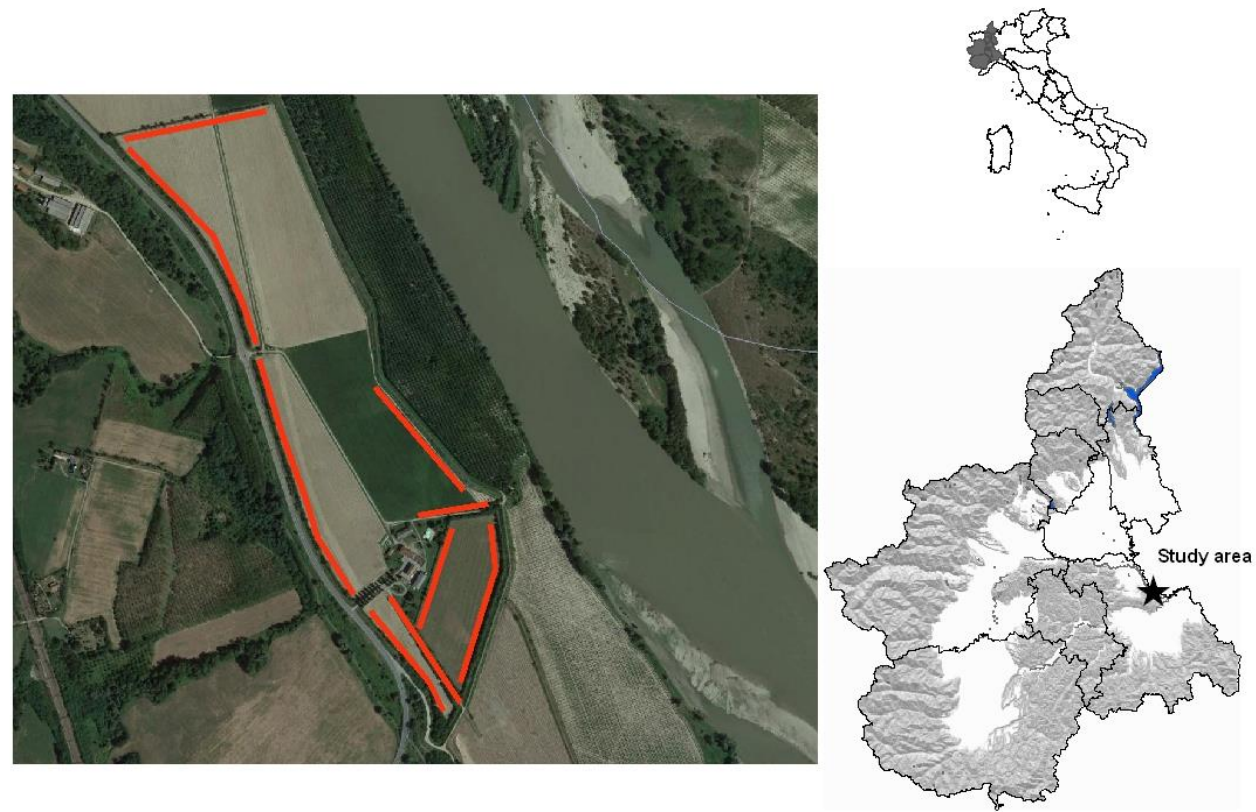

\section{Experimental design}

Bat activity was investigated using a SM2BAT+ automatic bat detector (Wildlife Acoustique Inc.) on stereo mode, with two microphones placed $1.5 \mathrm{~m}$ above the ground and oriented in opposite directions, one placed right next to the hedges, the other in an open space $60 \mathrm{~m}$ away from the hedges, in order to simultaneously capture activity and differences in activity. Real time recordings were made at a sampling frequency of $192 \mathrm{KHz}$ and an activation frequency of $-18 \mathrm{bB}$ and $8 \mathrm{~Hz}$.

Recordings were made at 8 sites, four for each hedge type, between May and September in 2013 and 2014. A total of 16 nights of sampling, eight per year, from dusk 'til dawn were carried out; recordings were made on clear nights, with wind strength below $6 \mathrm{~m} / \mathrm{s}$ and temperatures above $10^{\circ} \mathrm{C}$, to avoid measuring a decrease in bat activity due to climatic factors.

\section{Sound analysis and species identification}

Sequence identification of the recordings was carried out using Sonochiro ${ }^{\circledR}$ 3.3.2 software (Biotope Society, France) for automatic identification of echolocation signals. This program allows for the identification of bats echolocation signals in a given recording and for their classification at a homogeneous species group level, hence of species. It attributes a reliability index from 0 to 10 to each signal and allows to simultaneously detect up to three species per sequence.

To evaluate identification efficacy and to identify a reliability index threshold necessary for considering a sequence as correctly classified at group and species level, 372 preliminary 
Toffoli R.: The importance of linear landscape elements for bats in a Farmland area: the influence of height on activity

echolocation sequences were made to train the algorithm to identify 30 species. The results were analysed using GLMM and the probability of mistaken identification for each value of the reliability index was calculated. Using a score of the reliability index equal to or more than 4 , the probability of mistaken identification was below $5 \%$ for groups and species $(95 \%$ confidence interval for the groups: $3.3 \%-4.3 \%$; $95 \%$ confidence interval for the species 2.8\%-3.6\%). As a precautionary measure, only sequences identified at species level with a value equal to or more than 5 were considered. For those with a value inferior to 5 , the group species identified using the same method were used. All sequences that did not fall within these criteria were manually identified following guidelines by Barataud (2012). All signals belonging to the Myotis genus, due to the difficulties encountered in identifying them at species level (Russo \& Jones, 2002), even those classified at a specific level, were incorporated to the two groups indicated by the automatic identification software: Myotis LF (Myotis myotis and Myotis oxignathus) and Myotis HF (all other species). The same procedure was applied to the Plecotus genus signals that were all attributed to the group.

\section{Data analysis}

To describe activity levels along hedges and in open spaces, the number of passes per hour of each different species and groups were used (Barataud, 2012). A pass is defined as a recording consisting of at least one echolocation signal (call) up to a total length of $5 \mathrm{sec}$ (Thomas \& West, 1989; Barataud, 2012). Sequences exceeding this length were broken up into $5 \mathrm{sec}$ long sequences. For each sequence, feeding buzz calls were identified as a measure of foraging activity (sequence of signals emitted by bats while catching a prey) (Griffin et al., 1960).

Each identified taxon was assigned to the following guilds: open-habitat foragers Eptesicus serotinus, Hypsugo savii, Nyctalus noctula, Pipistrellus nathusii; edge-habitat foragers Pipistrellus kuhlii, Pipistrellus pipistrellus, Pipistrellus kuhlii/nathusii, closed-habitat foragers Myotis LF, Myotis HF, Plecotus sp. Assignment of species to the three guilds was based upon descriptions by Fenton (1989) and Muller et al. (2012) and on the type of habitat visited as well as on the type of foraging behaviour (Schnitzler \& Kalko 2001, Dietz et al., 2009). The group Pipistrellus kuhlii/nathusii was assigned to the edge-habitat forager guild given the high frequency of Pipistrellus kuhlii presence compared to Pipistrellus nathusii in the study area.

To examine the activity of a single species and of their relative guilds along the hedges and in open species, analyses of variance was applied (one-way ANOVA), following adequate transformation of samples in $\log _{\mathrm{e}}+1$, applying multiple post hoc comparisons using a Bonferroni test with significance level of $p>0.05$. The D'Agostino-Pearson normality test was applied to verify the normal distribution of data and the Levene test to ensure homogeneity of variance.

As no significant difference in activity levels was detected between the data sets, the 2013 and 2014 data were considered together $(t=-0.035, \mathrm{df}=254 ; \mathrm{p}=0.972)$.

\section{RESULTS}

\section{Species richness}

A total of 5784 sequences were recorded, 124 of which contained a feeding buzz $(2.14 \%)$, identifying 10 taxa, 6 of which at species level and 4 at group level (Table1). $44.84 \%$ of the recorded sequences belong to the Pipistrellus kuhlii/nathusii group, followed by the Pipistrellus kuhlii and Hypsugo savii species with respectively $27.76 \%$ and $10.67 \%$ of the sequences. Other taxa were represented by a smaller percentage of sequences $(<10 \%) .10$ 
taxa were identified along hedges with trees (100\% of the total), 6 along hedges without trees (60\% of total) and 7 in open spaces (70\% of total).

Table 1: List of taxa and overall number of contacts per habitat type

\begin{tabular}{|l|c|c|c|c|}
\hline \multicolumn{1}{|c|}{ Taxon } & $\begin{array}{c}\text { Hedge } \\
\text { sparse trees }\end{array}$ & $\begin{array}{c}\text { Hedge } \\
\text { no trees }\end{array}$ & $\begin{array}{c}\text { Open } \\
\text { space }\end{array}$ & Total \\
\hline Eptesicus serotinus & $18(0.65 \%)$ & & & $18(0.31 \%)$ \\
\hline Hypsugo savii & $164(5.92 \%)$ & $382(15.24 \%)$ & $71(13.92 \%)$ & $617(10.67 \%)$ \\
\hline Myotis LF & $6(0.22 \%)$ & & & $6(0.10 \%)$ \\
\hline Myotis HF & $144(5.20 \%)$ & $192(7.66 \%)$ & $12(2.35 \%)$ & $348(6.02 \%)$ \\
\hline Nyctalus noctula & $92(3.32 \%)$ & $44(1.76 \%)$ & $39(7.65 \%)$ & $175(3.03 \%)$ \\
\hline Pipistrellus kuhlii & $680(24.57 \%)$ & $744(29.69 \%)$ & $66(12.94 \%)$ & $1490(25.76 \%)$ \\
\hline Pipistrellus kuhlii/nathusii & $1240(44.80 \%)$ & $1116(44.53 \%)$ & $239(46.86 \%)$ & $2595(44.87 \%)$ \\
\hline Pipistrellus nathusii & $376(13.58 \%)$ & $28(1.12 \%)$ & $77(15.10 \%)$ & $481(8.32 \%$ \\
\hline Pipistrellus pipistrellus & $40(1.45 \%)$ & & $6(1.18 \%)$ & $46(0.80 \%)$ \\
\hline Plecotus sp & $8(0.29 \%)$ & & & $8(0.14 \%)$ \\
\hline Total & $2768(100.00 \%)$ & $2506(100.00 \%)$ & $510(100.00 \%)$ & $5784(100.00 \%)$ \\
\hline
\end{tabular}

The average number of taxa detected in the three surveyed habitats (Fig.2) varied significantly $\left(\mathrm{F}_{2,253}=14.72, \mathrm{p}<0.0001\right)$. More specifically, the average number of species per hour was of $4.15 \pm 0.22 \mathrm{SE}$ for hedges with trees, of $3.05 \pm 0.11 \mathrm{SE}$ for hedges without trees and of $2.46 \pm 0.17 \mathrm{SE}$ for open spaces (Fig.1). The Bonferroni test for multiple comparisons also points to a significant difference between the habitat pairs considered (Hedge sparse trees $v$ s Hedge no trees: $\mathrm{t}=3.57, \mathrm{p}<0.05$; Hedge sparse trees $v$ s Open space: $\mathrm{t}=5.38, \mathrm{p}<0.05$; Hedge no trees $v$ s Open space: $\mathrm{t}=2.75, \mathrm{p}<0.05)$.

Fig. 2: Number of taxa/hour for type of hedge

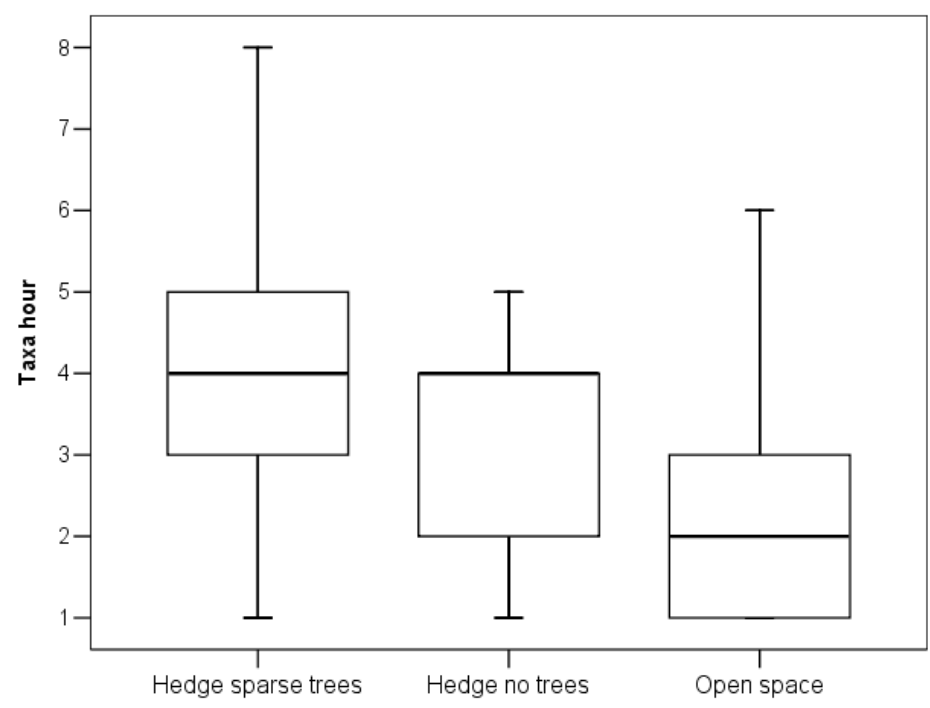


Toffoli R.: The importance of linear landscape elements for bats in a Farmland area: the influence of height on activity

\section{Bat activity}

Bat flight activity in the three habitats (Fig.3) significantly varied $\left(\mathrm{F}_{2,253}=32.75, \mathrm{p}<0.0001\right)$. Hedges with sparse trees present an index of 43.25 $\pm 6.21 \mathrm{SE}$ contacts/hour, hedges without trees of $18.49 \pm 0.75 \mathrm{SE}$ contacts/hour and open spaces of 9.22 $\pm 1.24 \mathrm{SE}$ (Fig.2). The Bonferroni test for multiple comparisons highlights a significant difference for pairs of habitats with hedges $v s$ open spaces $(\mathrm{t}=6.88, \mathrm{p}<0.05)$ and hedges without trees $v s$ open spaces $(\mathrm{t}=7.55, \mathrm{p}<0.05)$, whereas no significant differences were seen in hedges with trees $v s$ hedges without trees $(\mathrm{t}=0.39, \mathrm{p}>0.05)$.

\section{Fig. 3: Total number of contacts/hour for type of hedge}

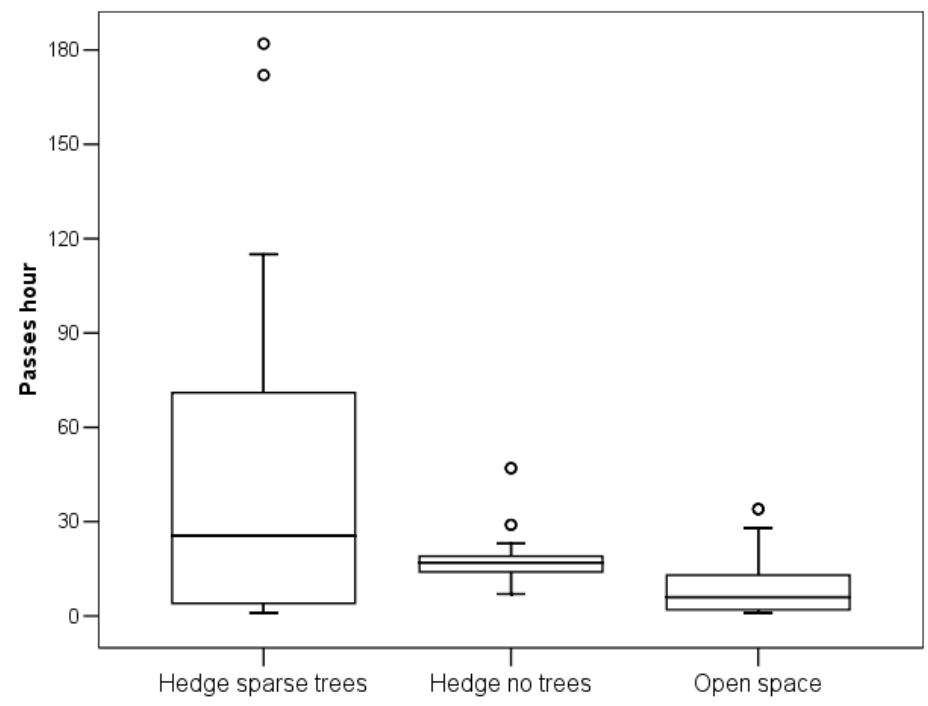

The various taxa observed exhibited different types of activity in the three surveyed habitats (Fig.4). Six of these were detected in all three habitats (Hypsugo savii, Myotis HF, Nictalus noctula, Pipistrellus kuhlii, Pipistrellus kuhlii/nathusii, Pipistrellus nathusii), whereas Eptesicus serotinus, Myotis LF and Plecotus sp. were only observed along hedges with sparse trees. Of these taxa, only Nyctalus noctula did not exhibit significant activity differences $\left(\mathrm{F}_{2,40}=0.17, \mathrm{p}=0.839\right)$ with an average contacts/hour number analogous in the three habitats (average Hedge sparse trees: $4.60 \pm 0.81 \mathrm{SE}$; average Hedge no trees: $3.66 \pm 0.83$ SE; average Open space: $3.54 \pm 0.43$ SE). Pipistrellus kuhlii showed a significant difference in activity in the three habitats $\left(\mathrm{F}_{2,183}=14.44, \mathrm{p}<0.0001\right)$ with a visiting index of $14.17 \pm 2.38 \mathrm{SE}$ contacts/hour in hedges with trees, of $6.64 \pm 0.74 \mathrm{SE}$ contacts/hour in hedges without trees and of $2.61 \pm 0.36 \mathrm{SE}$ in open spaces. Hypsugo savii $\left(\mathrm{F}_{2,18}=8.69, \mathrm{p}<0.0001\right)$ and the group Myotis HF $\left(\mathrm{F}_{2,119}=5.36, \mathrm{p}=0.006\right)$ present significant differences in the average counts of contacts/hour. The first species present an average visiting index of $5.85 \pm 1.03 \mathrm{SE}$ along hedges with sparse trees, of $4.83 \pm 0.17$ along hedges without trees and of $3.00 \pm 0.30 \mathrm{SE}$ in open spaces. Myotis HF presents an average visiting index of 3.60 \pm 10.80 SE along hedges with sparse trees, of $2.66 \pm 0.14 \mathrm{SE}$ along hedges without trees and of $1.20 \pm 0.13 \mathrm{SE}$ in open spaces. The Bonferroni post hoc test highlights significant differences both between hedges with trees $v s$ open spaces (Hypsugo savii: $\mathrm{t}=2.48, \mathrm{p}<0.05 ;$ Myotis $\mathrm{HF}: \mathrm{t}=2.93, \mathrm{p}<0.05$ ) between hedges without trees vs open spaces (Hypsugo savii: $\mathrm{t}=4.18, \mathrm{p}<0.05$; Myotis $\mathrm{HF}$ : $\mathrm{t}=3.25, \mathrm{p}<0.05$ ), whereas no activity differences between the two hedge types were detected 
(Hypsugo savii: $\mathrm{t}=1.30, \mathrm{p}>0.05 ;$ Myotis $\mathrm{HF}: \mathrm{t}=0.31, \mathrm{p}>0.05$ ). Pipistrellus nathusii shows significant differences in activity $\left(\mathrm{F}_{2,84}=7.09, \mathrm{p}=0.001\right)$ with an average number of contacts/hour of $7.83 \pm 1.32 \mathrm{SE}$ along hedges with sparse trees, of $3.50 \pm 0.46 \mathrm{SE}$ along hedges with no trees and of $2.33 \pm 0.28 \mathrm{SE}$ in open spaces. The difference between habitat pairs is only significant between hedges with trees $v s$ open spaces $(\mathrm{t}=3.71, \mathrm{p}<0.05)$ whereas it is not between hedges with trees $v s$ hedges without trees $(\mathrm{t}=0.68, \mathrm{p}>0.05)$ and hedges with no trees and open spaces $(\mathrm{t}=1.15, \mathrm{p}>0.05)$.

Fig. 4: Average number of contacts/hour $( \pm \mathrm{SE})$ for each taxa for type of hedge

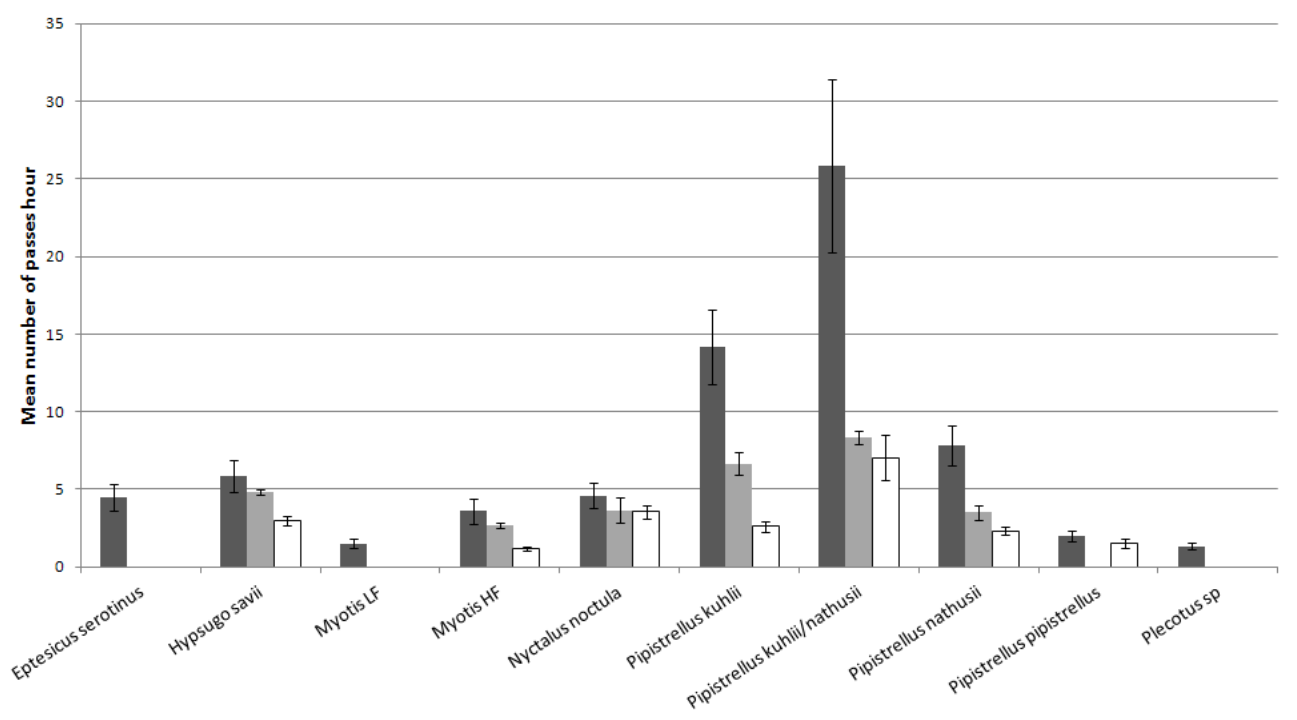

The guilds (Fig.5) present a significant difference in their activity in the three habitats considered (closed-habitat foragers: $\mathrm{F}_{2,119}=6.08, \mathrm{p}=0.03$; edge-habitat foragers: $\mathrm{F}_{2,233}=15.06$, $\mathrm{p}<0.0001$; open-habitat foragers: $\mathrm{F}_{2,189}=19.04$, $\mathrm{p}<0.0001$ ). The Bonferroni post hoc test highlights a significant difference in activity for closed-habitat foraging species between hedges with trees $v s$ open spaces $(\mathrm{t}=3.41, \mathrm{p}<0.05)$ and between hedges with no trees $v s$ open spaces $(t=3.26, p<0.05)$ whereas there is no difference between the two hedge types $(t=0.52$, $\mathrm{p}>0.05)$. This difference can also be observed in edge-habitat foraging species, whose activity is significantly higher in hedges with trees than in open spaces $(t=9.94, p<0.05)$ and in hedges without trees than in open spaces $(\mathrm{t}=12.88, \mathrm{p}<0.05)$, whereas no differences are seen between the two hedge types. Open-habitat foraging species present a significantly increased activity between hedges with trees $v s$ hedges with no trees $(\mathrm{t}=5.41, \mathrm{p}<0.05)$ and between hedges with trees $v s$ open spaces $(\mathrm{t}=4.49, \mathrm{p}<0.05)$, but there is no difference between hedges without trees $v s$ open spaces $(\mathrm{t}=0.10, \mathrm{p}>0.05)$. 
Toffoli R.: The importance of linear landscape elements for bats in a Farmland area: the influence of height on activity

Fig. 5: Average number of contacts/hour $( \pm \mathrm{SE})$ of bat guild for type of hedge

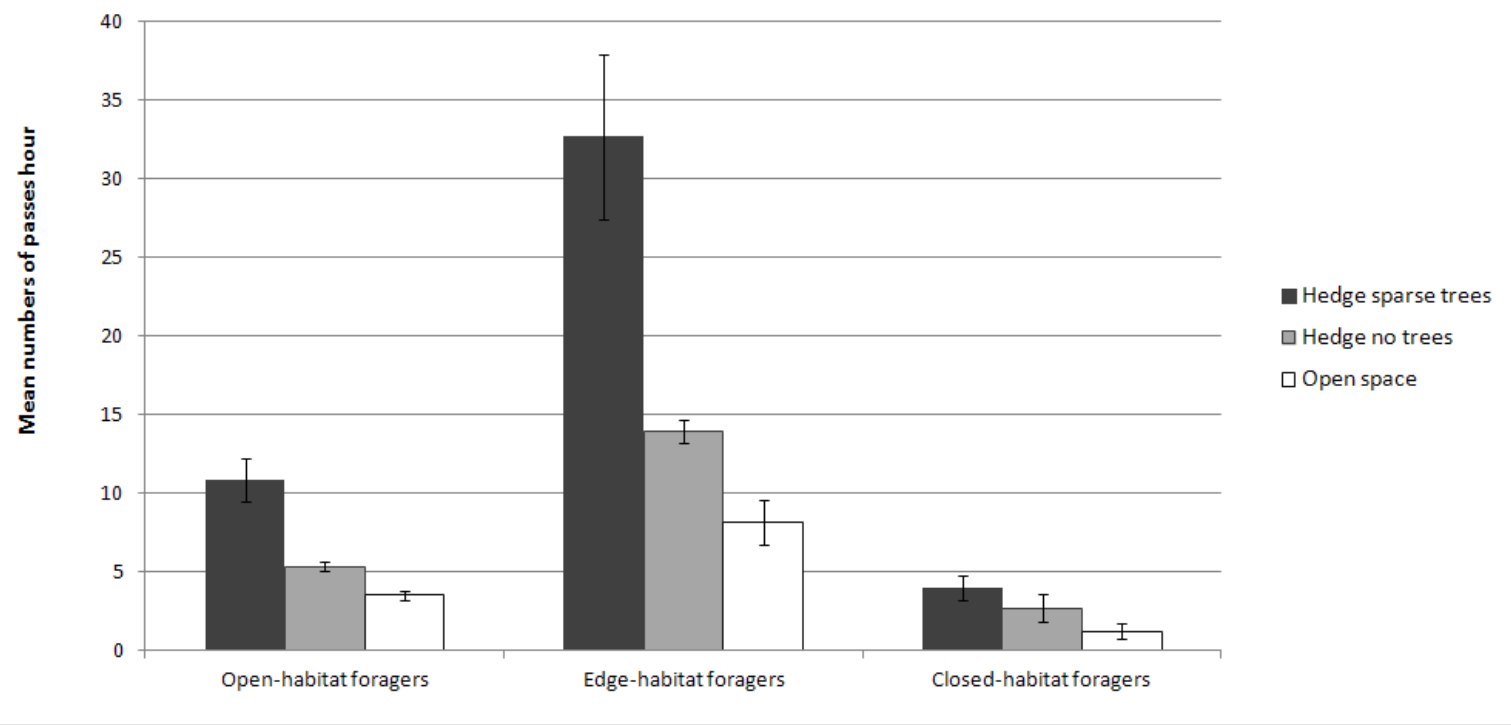

With regards to foraging activity (Fig.6), the average feeding buzz/hour count presents significant differences according to the analysed landscape elements $\left(\mathrm{F}_{2,31}=7.05 ; \mathrm{p}=0.003\right)$ (Fig.5). The post hoc test highlights a higher foraging activity in hedges with trees than in hedges without trees $(\mathrm{t}=3.04 ; \mathrm{p}<0.05)$ and in hedges with trees than in open spaces $(\mathrm{t}=2.92$; $\mathrm{p}<0.05)$ whereas no differences were seen between hedges without trees $v s$ open spaces $(\mathrm{t}=0.16 ; \mathrm{p}>0.05)$. Foraging activity of the three guilds appears different (Fig.7). For closed-habitat foragers feeding buzzes were detected only along hedges with trees, whereas open-habitat foragers did not show differences in foraging activity in the three surveyed landscape elements $\left(\mathrm{F}_{2,5}=0.22 ; \mathrm{p}=0.805\right)$. The edge-habitat foraging species present a significantly different activity in the three elements considered $\left(F_{2,26}=7.85 ; p=0.002\right)$. The Bonferroni post hoc test points to a significant difference for this guild between hedges with trees $v s$ open species $(\mathrm{t}=3.62, \mathrm{p}<0.05)$, between the two hedge types and between hedges without trees $v s$ open spaces. 
Fig. 6: Average overall number of feeding buzz/hour $( \pm \mathrm{SE})$ for type of hedge

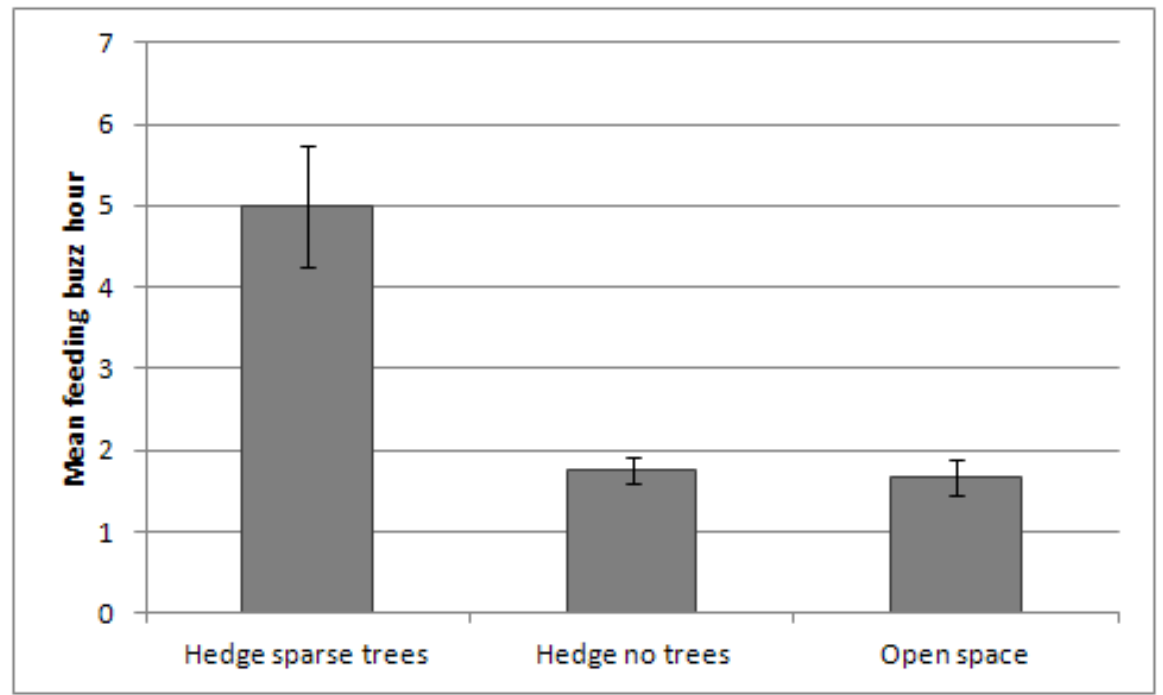

Fig. 7: Average number of feeding buzz/hour $( \pm$ SE) for each bat guild for type of hedge

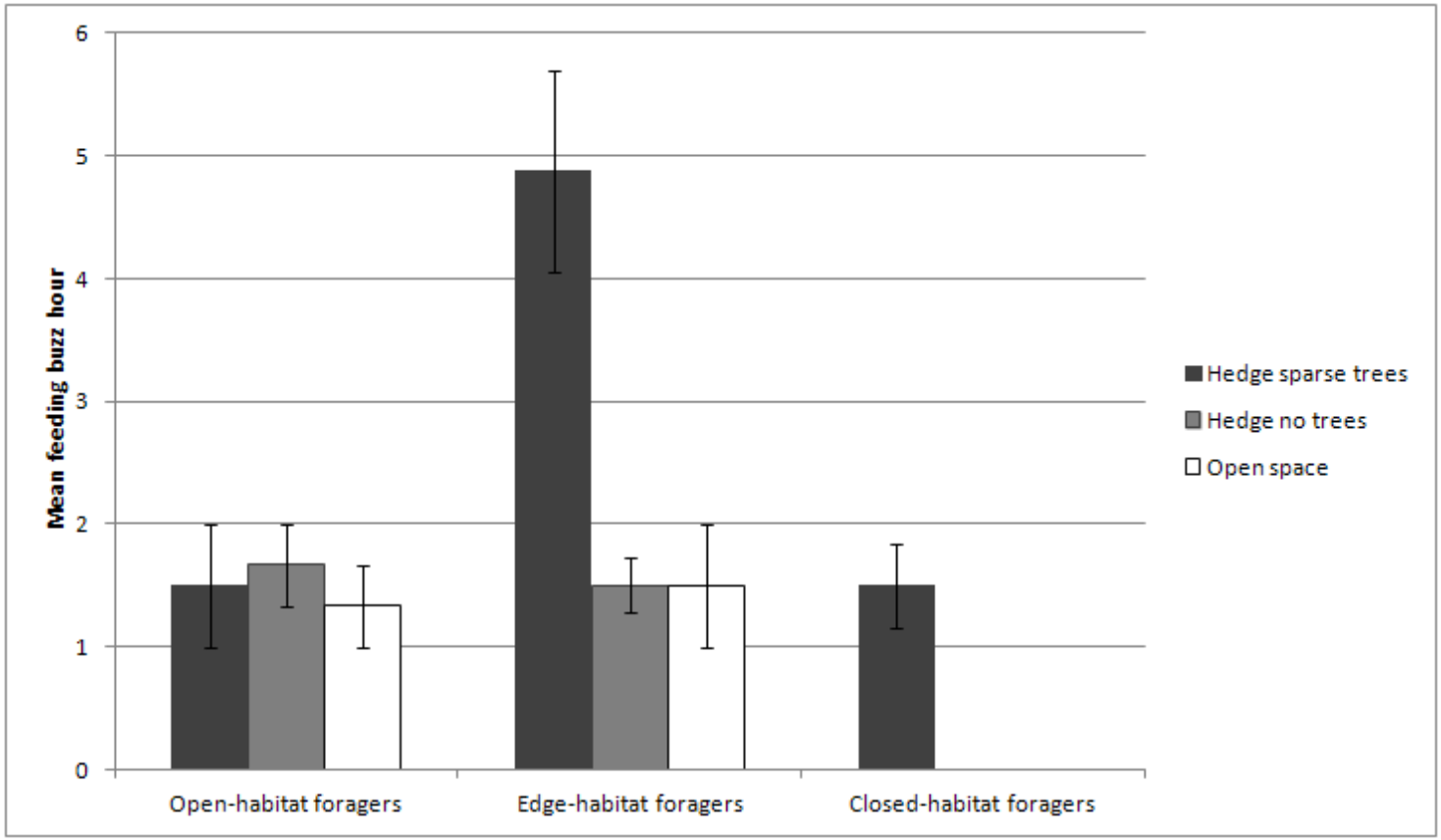


Toffoli R.: The importance of linear landscape elements for bats in a Farmland area: the influence of height on activity

\section{DISCUSSION}

Hedge and hedgerows are important landmarks for bats in agro-systems (Limpens \& Kapteyn, 1991; Verboom \& Huitema, 1997; Boughey et al., 2011; Kelm et al., 2014). This project highlights the differences in bat activity levels along hedges of variable height and composition compared to farmland open spaces. The greatest richness of species was observed along hedges; the same was confirmed for flight and foraging activity, which was greater than in open spaces. This phenomenon was further accentuated along hedges with sparse trees compared to low hedges without trees, both at an overall level and for individual species. Pipistrellus kuhlii, one of the most active farmland bat species (Russo \& Jones, 2003), shows higher activity along hedges with trees as opposed to hedges without trees or open spaces.

The presence of trees along hedges, in fact, can be beneficial for bats, that can benefit from greater protection from predators and from meteorological threats (Limpens \& Kapteyn, 1991; Verboom \& Spoelstra, 1999). Additionally, the abundance of insects in the vicinity of hedges tends to be greater as a function of increasing hedge height (Lewis, 1967, 1969). Hedges with trees can also provide additional microhabitats containing aged trees and dead wood, which increase the abundance of invertebrates and biodiversity (DEFRA, 2010).

The differences in activity indices detected between the two hedge types and open spaces are to be related to the ecological niches of different species and to their different foraging behaviours. Some species of the Myotis genus are considered as gleaning bats, with broad wings, are adapted to foraging in thick vegetation where they capture stationary prey and produce echolocation signals of modulated frequency (Dietz et al, 2009). Nyctalus noctula and Pipistrellus nathusii are considered as hawking bats because of their long, narrow wings, their fast flight and because they are capable of producing echolocation signals of almost constant frequencies (Norberg \& Rayner, 1987; Neuweiler, 1989; Dietz et al., 2009) and of capturing prey in open spaces. The open-habitat foraging species only present significant differences in flight activity along hedges with sparse trees, but no differences are seen between low hedges $v s$ open spaces. No significant differences between groups are observed in foraging activity. For species belonging to the open-habitat foraging guild, low hedges cannot be considered as important landscape elements for their commuting behaviour at higher altitudes and in open spaces lacking obstacles (Dietz et al., 2009). Hedges with trees can represent physical landscape elements that can be followed during commuting or used to define foraging areas. In fact, Nyctalus noctula, uses different open habitats for its foraging activity, yet foraging areas are often well defined by landscape elements (Vaughan et al., 1997; Mackie \& Racey, 2007). On the contrary, closed-habitat foraging species display a significantly higher activity along hedges without trees and foraging behaviour only along hedges with sparse trees. This ought to be related to their commuting and foraging behaviour at low altitude from ground level (Dietz et al., 2009) that also makes low hedges important landscape elements. Even for the edge-habitat foraging species activity is higher along hedges, with or without trees, than in open spaces; the same trend is observed in their foraging behaviour, during which hedges with trees are preferred.

The results of this experiment highlight the importance of correct management of farmland linear landscape elements in context of bat conservation, including the reactivation of new hedges as expected by agro-environmental measures of EU agricultural policies. Many bat species can, in fact, benefit from the addition of hedges to agrosystems, otherwise characterized by large open spaces lacking linear landscape elements, especially if these are structurally complex and contain sparse trees within them. The presence of trees favours commuting behaviour of all bat species, and especially facilitates foraging of closed-habitat 
species such as those belonging to the Plecotus and Myotis genus, and of edge-habitat species. Hedges with trees, as well as favouring bat activity, also present a number of advantages for the overall conservation of biodiversity. The abundance/presence of many bird and mammal species is influenced by the density of trees along hedges (Hinsley \& Bellamy, 2000; Walker et al., 2005; Kotzageorgis \& Mason, 1997; Michel et al., 2007), even if negative effects have been detected for species heavily depending on open spaces (DEFRA, 2010; Green et al, 1994). A critical tree density along hedges is hence advantageous, especially for bats, but careful evaluation of negative effects on ground-nesting species need to be taken into careful consideration.

\section{REFERENCES}

Antrop, M., (2005). Why landscapes of the past are important for the future. Landscape and Urban Planning, 70, 21-34.

Baltensperger, B.H., (1987). Hedgerow distribution and removal in non forested regions of the Midwest. Journal of Soils and Water Conservation, 42, 60-64.

Barataud, M,. (2012). Ecologie acoustique des chiroptères d'Europe. Biotope Édition, Mèze. Muséum national dHistoire naturelle, Paris.

Benton, T.G., Vickery, J.A. \& Wilson, J.D. (2003). Farmland biodiversity: is habitat heterogeneity the key? Trends in Ecology \& Evolution, 18, 182-188.

Bianchi, F.J.J.A., Booij, C.J.H. \& Tscharntke, T., (2006). Sustainable pest regulation in agricultural landscapes: a review on landscape composition, biodiversity and natural pest control. Proceedings of the Royal Society Biological Sciences. 273, 1715-1727. Retrieved March 30, 2006, from: http://dx.doi. org/10.1098/rspb.2006.3530.

Boughey, K. L., Lake, I. R., Haysom, K. A. \& Dolman, P. M. (2011). Improving the biodiversity benefits of hedgerows: How physical characteristics and the proximity of foraging habitat affect the use of linear features by bats. Biological Conservation, 144, 17901798.

Burel, F. (1996). Hedgerows and their role in agricultural landscapes. Critical Reviews in Plant Sciences, 15, 169-190.

DEFRA (2010). Trends, Long Term Survival and Ecological Values of Hedgerow Trees: Development of Populations Models to Inform Strategy. Forest Research, Forestry Commission. Report to the UK Government Department for the Environment, Food and Rural Affairs, London.

Dietz, C., von Helversen, O. \& Nill, D., (2009). Bats of Britain, Europe and Northwest Africa. A. \& C. Black: London.

Dover, J. \& Sparks, T., (2000). A review of the ecology of butterflies in British hedgerows. Journal of Environmental Management, 60, 51-63.

Downs, N. C. \& Racey. P. A., (2006). The use by bats of habitat features in mixed farmland in Scotland. Acta Chiropterologica, 8, 169-185.

Entwistle, A. C., Racey, P. A. \& J. R. Speakman, (1996). Habitat exploitation by a gleaning bat, Plecotus auritus. Philosophical Transactions of the Royal Society, 351B: 921-931

Fenton, M.B., (1989). The foraging behaviour and ecology of animal eating bats. Canadian Journal of Zoology . 68, 411-421. 
Toffoli R.: The importance of linear landscape elements for bats in a Farmland area: the influence of height on activity

Green, R. E., Osborne, P. E. \& Sears, E. J., (1994). The distribution of passerine birds in hedgerows during the breeding season in relation to characteristics of the hedgerow and adjacent farmland. Journal of Applied Ecology, 31, 677-692.

Griffin, D.R., Webster, F.A. \& Michael, C.R., (1960). The echolocation of flying insects by bats. Animal Behaviour, 8, 141-154.

Hannon, L.E., (2009). Hedgerows in an agri-natural landscape: potential habitat value for native bees. Biological Conservation, 142, 2140-2154.

Hinsley, S. A. \& Bellamy, P. E., (2000). The influence of hedge structure, management and landscape context on the value of hedgerows to birds: a review. Journal of environmental management, 60(1): 33-49.

Hinsley, S.A., Bellamy, P.E., (2000). The influence of hedge structure, management and landscape context on the value of hedgerows to birds: a review. Journal of Environmental Management, 60, 33-49.

Kelm, D. H., Lenski, J., Kelm, V., Toelch, U., \& Dziock, F., (2014). Seasonal bat activity in relation to distance to hedgerows in an agricultural landscape in central Europe and implications for wind energy development. Acta Chiropterologica, 16, 65-73.

Kotzageorgis, G. C. \& Mason, C. F., (1997). Small mammal populations in relation to hedgerow structure in an arable landscape. Journal of Zoology, 242, 425-434.

Krull, D., Schumm, A., Metzner, W. \& Neuweiler, G., (1991). Foraging areas and foraging behavior in the notch-eared bat, Myotis emarginatus (Vespertilionidae). Behavioral Ecology and Sociobiology, 28, 247-253.

Jonsen, I.D. \& Fahrig, L., (1997). Response of generalist and specialist insect herbivores to landscape spatial structure. Landscape Ecology, 12,185-197. Retrieved March 3, 2000, from DOI:http://dx.doi.org/10.1023/A:1007961006232.

Lewis, T., (1967). The horizontal and vertical distribution of flying insects near artificial windbreaks. Annals of Applied Biology, 60, 23-31.

Lewis, T., (1969). The distribution of flying insects near a low hedgerow. Journal of Applied Ecology, 6, 443-452.

Limpens, H.J.G.A. \& Kapteyn, K., (1991). Bats, their behaviour and linear landscape elements. Myotis,29: 39-48.

Mackie, I. J. \& Racey, P. A., (2007). Habitat use varies with reproductive state in noctule bats (Nyctalus noctula): implications for conservation. Biological Conservation, 140(1), 70-77.

Maudsley, M. J., (2000). A review of the ecology and conservation of hedgerow invertebrates in Britain. Journal of Environmental Management, 60, 65-76.

Michel, N., Burel, F., Legendre, P. \& Butet, A., (2007). Role of habitat and landscape in structuring small mammal assemblages in hedgerow networks of contrasted farming landscapes in Brittany, France. Landscape Ecology, 22(8), 1241-1253.

Müller, J., Mehr, M., Bässler, C., Fenton, M. B., Hothorn, T., Pretzsch, H.,\& Brandl, R., (2012). Aggregative response in bats: prey abundance versus habitat. Oecologia, 169(3), 673-684.

Norberg, U. M. \& Rayner, J. M., (1987). Ecological morphology and flight in bats (Mammalia; Chiroptera): wing adaptations, flight performance, foraging strategy and echolocation. Philosophical Transactions of the Royal Society B: Biological Sciences, 316, $335-427$. 
Neuweiler, G., (1989). Foraging ecology and audition in echolocating bats. Trends in Ecology \& Evolution, 4(6), 160-166.

Pollard, K.A. \& Holland J. M., (2006). Arthropods within the woody element of hedgerows and their distribution pattern. Agricultural and Forest Entomology, 8, 203-211.

Regione Piemonte, ( 2015). Programma di sviluppo rurale 2014-2020. Regione PiemonteMinistero delle politiche agricole, alimentari e forestali.

Robinson, R.A., Wilson, J.D. \& Crick, H.Q.P., (2001). The importance of arable habitat for farmland birds in grassland landscapes. Journal of applied Ecology, 38,1059-1069. Retrieved April 30, 2006, from DOI:http://dx.doi.org/10.1046/j.1365-2664.2001.00654.x.

Robinson, R. A. \& Sutherland, W. J., (2002). Post-war changes in arable farming and biodiversity in Great Britain. Journal of applied Ecology, 39(1), 157-176.

Russo, D. \& Jones, G., (2002). Identification of twenty-two bat species (Mammalia: Chiroptera) from Italy by analysis of time-expanded recordings of echolocation calls. Journal of Zoology. London. 58, 98-103.

Russo D. \& Jones G., (2003). Use of foraging habitats by bats (Mammalia: Chiroptera) in a Mediterranean area determined by acoustic surveys: conservation implications. Ecography, 26, 197-209.

Schaub, A. \& Schnitzler H.U., (2007). Flight and echolocation behaviour of three vespertilionid bat species while commuting on flyways. Journal of Comparative Physiology, 193, 1185-1194.

Schnitzler, H.U. \& Kalko E.K.V., (2001). Echolocation by insect-eating bats. Bioscience, 51, 557-569

Schnitzler, H.U., Moss C. F. \& Denzinger A., (2003). From spatial orientation to food acquisition in echolocating bats. Trends in Ecology and Evolution, 18, 386-394.

Sklenicka, P., Molnarova, K., Brabec, E., Kumble, P., Pittnerova, B., Pixova, K. \& Salek, M., (2009). Remnants of medieval field patterns in the Czech Republic: analysis of driving forces behind their disappearance with special attention to the role of hedgerows. Agriculture, Ecosystems \& Environment, 129, 465-473.

Tattersall, F.H., Macdonald, D.W., Hart, B.J., Johnson, P., Manley, W. \& Feber, R., (2002). Is habitat linearity important for small mammal communities on farmland? Journal of Applied Ecology , 39: 643-652.

Thomas, D. W. \& West S. D., (1989). Sampling methods for bats. United States Forest Service General Technical Report, PNW, 243, 1-20.

Vaughan, N., Jones, G. \& Harris, S., (1997). Habitat use by bats (Chiroptera) assessed by means of a broad-band acoustic method. Journal of Applied Ecology, 34, 716-730.

Verboom, B. \& Huitema H., (1997). The importance of linear landscape elements for the pipistrelle Pipistrellus pipistrellus and the serotine bat Eptesicus serotinus. Landscape Ecology, 12, 117-125.

Verboom, B. \& Spoelstra K., (1999). Effects of food abundance and wind on the use of tree lines by an insectivorous bat, Pipistrellus pipistrellus. Canadian Journal of Zoology, 77, 1393-1401.

Walker, M. P., Dover, J. W., Hinsley, S. A. \& Sparks, T. H., (2005). Birds and green lanes: Breeding season bird abundance, territories and species richness. Biological conservation, 126(4), 540-547. 
Toffoli R.: The importance of linear landscape elements for bats in a Farmland area: the influence of height on activity

Walsh, A. L. \& Harris S., (1996). Foraging habitat preferences of verpertilionid bats in Britain. Journal of Applied Ecology, 33, 508-518.

Weibull, A.-C., Östman, Ö. \& Granqvist, A., (2003). Species richness in agroecosystems: the effect of landscape, habitat and farm management. Biodiversity and Conservation, 12, 13351355.

Whittingham, M.J., Krebs, J.R., Swetnam, R.D., Thewlis, R.M., Wilson, J.D. \& Freckleton, R.P., (2009). Habitat associations of British breeding farmland birds. Bird Study, 56, 43-52. 